\title{
Er luthersk politisk teologi valgbeslægtet med liberalisme og republikanisme?
}

\author{
Professor Dr. Heinrich Assel
}

Svend Andersen, Macht aus Liebe. Zur Rekonstruktion einer lutherischen politischen Ethik. TBT 149. Berlin - New York: de Gruyter 2010. XII + 329 s.

Abstract: Svend Andersen's book Macht aus Liebe (Love in Power) is a vital contribution to the discussion about the affiliation of various political theologies to liberalism. The book contains of substantial, refreshingly provocative reconstruction of the political ethics in Luther and Danish Luthernism in the spirit of political liberalism from Kant to Rawls and Habermas' republicanism; and is a genuine Danish contribution to an European comparative analyses of political confessional cultures.

Key words: Svend Andersen - Political ethics - confessional cultures Martin Luther - Lutheranism - republicanism - Two-kingdoms-doctrine - charismatic authority - political judgment

Med bogen Macht aus Liebe placerer Svend Andersen sig midt i den virulente diskussion om, hvorvidt den politiske teologi i monoteistiske religioner overhovedet kan forbindes med moderne liberal tankegang, og om hvordan religionspolitikken bør udformes i europæiske demokratier. Med udgangspunkt i den politiske liberalisme leveres her en substantiel og forfriskende stridslysten rekonstruktion af både Luthers politiske etik og den danske borgerlige lutherdom og den tysk-prøjsiske ditto. Andersen synes dermed at gøre et "valgslægtskab" gældende mellem luthersk etik og liberalismens ånd - på samme måde som Max Weber hævdede et "valgslægtskab" mellem kapitalismens ånd og calvinistisk etik.

I bogens tre store hovedkapitler rekonstruerer Andersen først (1) Luthers politiske teologi i dens helhed ud fra en skarpsindig og omhyggelig tolkning af relevante Luther-skrifter, først og fremmest i forlængelse af det såkaldte øvrighedsskrift fra 1523 (11-84). Denne rekonstruktion forbindes med et meget kort udblik til den tidligt-mo- 
derne lutherdoms 250 år gamle "paradoks", eksemplificeret med Danmark (84-89).

I andet hovedkapitel (2) opridser Andersen konturerne af forholdet mellem luthersk etik og det politisk moderne med udgangspunkt i Kants rets- og politik-teori - i sig selv et lille mesterværk fra Kanteksperten Andersens hånd (92-126). Det er svært at finde en lige så indholdsrig fremstilling af Kants etik i nutidig evangelisk etik. Kants prægning af den borgerlige lutherdom belyser Andersen ud fra tre store danskere, Martensen (127-162), som tildeles den største plads og sympati, Grundtvig (163-180) og Kierkegaard (180-209). Disse tre er på en gang hovedtænkerne i den danske demokratiseringsproces, men samtidig også antipoder. Dette kapitel er en fornem analyse af den politiske konfessionskultur i Danmarks "guldalder". Indkredsningen af de liberale spor i den tyske-prøjsiske lutherdom under kejsertiden og Weimar-republikken koncentrerer sig om den i samtiden såvel ensomme som betydningsfulde demokrat Ernst Troeltsch (212244), selvom han snarere står som den tyske Luther-renæssances antipode end som en repræsentant for den.

Den encyklopædiske gennemgang munder i tredje hoveddel (3) ud $\mathrm{i}$ en rekonstruktion af luthersk politisk etik i det 21. århundrede (298-314). Gennem en koncis diskussion med Rawls og Habermas opridser forfatteren sit eget standpunkt (245-298). I centrum står her den aktuelle politisk-etiske rekonstruktion af Luthers to-rige- og toregimente-lære samt en forstålse af naturlig politisk fornuft i forlængelse af den gyldne regel. Langt ud over Luthers tidsafhængige semantik, men dog med kravet om at være en nutidig fremskrivning af Luthers argumentative intention, bliver den gyldne regel forstået som en transcendentalpragmatisk og interpersonal reciprocitetsregel, hvor man "sætter sig i den andens sted" (303) - om forberedelsen af denne figur hos den unge Luther, se s 36-39. Beundringsværdigt klart fremfører forfatteren tre metodiske præmisser (4-9):

(1) Han rejser kravet om at fortage en normativ rekonstruktion af Luthers politiske etik: Denne rekonstruktion orienterer sig mod den politisk-etiske argumentationskerne, der meningsfuldt kan reformuleres og rekontekstualiseres i aktuelle afgørelser i forbindelse med $\mathrm{fx}$ menneskerettighedspolitik og krigsdeltagelse (8). På afgørende steder i undersøgelsen opstilles i alt seks argumenter (82f. 298f). Tre gengives her eksemplarisk:

c. Der christliche Glaube ist durch ein Handeln konstituiert, das nicht den Charakter menschlichen Machtausübens hat und das deshalb nicht auf den politischen Bereich übertragbar ist. d. Christliche Nächstenliebe ist eine komplexe Größe, die als Wohltun die Gestalt politischen Han- 
delns haben kann ... f. Es gibt eine universale Normativität in der Gestalt des natürlichen Gesetzes, das, zusammengefasst in der Goldenen Regel, als gemeinsame normative Grundlage für Christen und Nichtchristen dienen kann (82f. 298f).

Her må man spørge: Hvis sætning c. taler om en troskonstituerende (Guds-) handlen, dvs. hvis de nævnte grundsætninger implicerer en typik for guddommelig magthandling og ordhandling, så savner man i Andersens liste - også af metodiske grunde - en rekonstruktion af Luthers stands- og hierarkilære. Andersen fortolker den øjensynligt som en tidligt-moderne/feudal samfundsteori, som historien siden har falsificeret (fx s. 81) og ser i den (anderledes end fx O. Bayer og H.G. Ulrich) ingen rekonstruérbar politisk-teologiske kerne, der omfatter Guds institutionsformidlede retfærdighed og suverænitet. Betyder det, at denne teori om Guds kritisk-politiske skabelseshandling i bud, stænder og hierarki ikke længere kan reformuleres - og dermed heller ikke vendes imod institutioners egen systemtvang og egne systemkonflikter?

(2) Andersen aflægger endvidere regnskab over de begrebs- og samfundshistoriske forbindelser og semantiske forskydninger, der findes mellem henholdsvis Luthers og Kants - dog egentligt først mellem Luthers og Rawls' - argumenter. Den fortolkningsmæssige omhyggelighed er særlig fin i analysen af den vanskelige skelnen mellem offentlig og privat. Eksemplarisk klart viser Andersen de politisk-historiske brud i forståelsen af denne skelnen.

Den er hos Luther (a) forbundet med "hersker- og embedspersoner" som offentlige personer. ${ }^{1}$ Den er i oplysningen (b) forbundet med de "mediale meningsdannende fora" (publikum, læseroffentlighed, presse, den politiske offentlighed/den ikke offentlige politiske kultur). Den er i sidste ende $i$ dag (c) forbundet med forskellige "former for politisk retfærdiggørelse og begrundelse" (public reason; public political forum). ${ }^{2}$

Andersens bog kan hele vejen igennem bruges som manual til centrale grundbegrebers historie i luthersk politisk teori med den store gevinst, at begrebsanalysen er argumentativt integreret $\mathrm{i}$ teksterne. Gør man det, vil man dog bemærke, at vigtige grundbegreber mangler! Fx begrebet "ejendom" som del af treheden: frihed, lighed, ejendomsret! Vi møder hos Andersen kun treheden: frihed, lighed, of-

1. Man savner her en henvisning til Ernst Kantorowicz, The King's Two Bodies: A Study in Medieval Political Theology (Princeton: Princeton University Press 1975).

2. Til (a) kan der henvises til Luthers forståelse (40-43,79f), til (b) til Kants (118f), Martensens (157f) und Rawls (257-259) og til (c) til udredningerne vedr. Rawls $(258,264 \mathrm{f})$ og hans diskussion med Habermas. 
fentlighed (fx s. 77-78). ${ }^{3}$ Hvad betyder det på den ene side, at Kants retslære, der er forbilledet for Andersens modernitetskoncept, i virkeligheden udtrykker en privatretslig ejendoms- og kontraktteori (106108); mens vi på den anden side er nødt til at erstatte eksplicitte fejlskud hos Luther: libertas christiana bliver jo lige præcis ikke brugt til at udlede nogen privatretlig ejendomsret baseret på kontrakt som modstykket til de negative politiske frihedsrettigheder. ${ }^{4}$ I disse brudflader i brugen af grundbegreber griber forfatteren til konjekturer: En udarbejdet luthersk retslære mangler (55), men ville, havde vi haft en sådan, være "kongenialer Teil seiner politischen Theologie" (59). Hvad vi har, er dialektiske sondringer i brugen af forhåndenværende rettigheder (duplex, triplex iustitia), dydsregler for den vise fyrste (aequitas) og i sin kerne den gyldne regel som universel-normativ reciprocitets-regel.

Lige så klart det er, at Luthers retsteori må skelnes fra hans politiske etik, ligeså ensidigt koncentrerer Andersen sig om menneskeværdigheds- og menneskerettighedsparadigmet. Dermed forsvinder andre måske lige så modernitetsrelevante aspekter ved Luthers politiske etik og retslære ud af synsfeltet (statsret og strafferet). Samtidig rives der afgørende huller i rekonstruktionen, hvis vi vælger den liberale modernitetsteori som målestok (privatret og ejendomsindividualisme)!

(3) Andersen vælger på forhånd Max-Weber-perspektivet, der betragter det politiske ud fra magt- og legitimitetsteorier: Det er herredømmets fænomen som patriarkalsk bureaukrati og fremfor alt som karismatisk kærlighed, som udgør paradigmet i den politiske etik. Alternative paradigmer, som fx den politiske afgørelse sådan som det udfoldes i Oliver O'Donovans politiske teologi, eller den ekskluderende inklusion gennem en retssættende suverænitet, som i forestillingen om homo sacer hos Giorgio Agamben, diskuteres ikke.

I centrum af denne lutherske reception af Rawls' politiske liberalisme står rekonstruktionen af den gyldne regel, forstået som indbegrebet af naturlig-lovmæssig fornuft og dens reciprocitet.

Receptionen sigter mod (a) en institutionel formidlet og for så vidt interpersonel velgerning (Wohltun) ud af medmenneskelighed og næstekærlighed, men samtidig på en pluralisme-sensibel måde skolet

3. Det er klart, at transformationen af treheden frihed, lighed, ejendom (som den franske revolutions egentligt effektive formel) igennem længere tid i evangeliske etik har været fortrængt af treheden frihed, lighed, deltagelse. Cf. W. Huber og H.E. Tödt: Menschenrechte. Pespektiven einer menschlichen Welt (Stuttgart: Kreuz 1977). Men denne forskydning forbliver som retshistorisk heuristik tvivlsom.

4. På trods af den marginale henvisning i note 23 s. 56 - som snarere er undtagelsen, der bekræfter regelen! 
af Rawls: dvs. mod lutherske borgeres artikulationsduelige deltagelse i den politiske offentlighed. Lutherske borgere handler her som "embedspersoner", der accepterer de specifikke begrundelser for den magtudøvelse, der er forbundet hermed.

Receptionen af liberalismen sigter videre mod (b) lutherske borgeres offentlige artikulationsduelige deltagelse i det offentlige forum, dvs. i det civile samfunds mediale meningsdannelse.

Endelig stiler den (c) mod disse former for deltagelse i den offentlige politiske fornuft vel vidende, at i den interne kirkelige offentlighed (eller skulle man snarere sige: i offentligheden i politia Christi) leves et kristent borgerskab, der er uafviseligt individuelt og "inderligt". Kristenborgerens næstekærlighed kan forblive etisk "supererogatorisk" 5 og umulig at formulere inden for retten - selv inden for menneskerettighederne:

Lutherisch verstanden ist die Ethik der Nächstenliebe nicht ganz und gar mit einer universalen Ethik identisch... Das Eigenartige am diesbezüglichen Gedankengang Luthers besteht eben in der Annahme einer partialen Übereinstimmung zwischen der Nächstenliebe und einem Handeln nach der Goldenen Regel (302f).

Men hvad betyder delvis overensstemmelse mellem næstekærligheden og en handlen i overensstemmelse med den gyldne regel? Og hvad betyder delvis ikke-overensstemmelse mellem den kristnes grænseløse kærlighed og den praktisk-fornuftige, politiske form for næstekærlighed som velgerning (Wohltun) i betydningen liberal retfærdighed?

I Andersens (transcendentalpragmatiske og interpersonale) rekonstruktion af den gyldne regel, som han forstår som regulering og instruering af denne "sich in die Rolle des Anderen Versetzens" (303), viser næstekærlighedens overskud sig ikke først og fremmest i "overordentlige" handlinger. Den viser sig i en bestemt politisk forestilling, i troens genuint politiske forestillingsevne. Hvordan skal man ellers forstå en passage som den følgende? Den gyldne regel er "eine Aufforderung an unsere Phantasie. Die goldene Regel verlangt von uns, dass wir unser Vorstellungsvermögen mobilisieren und uns überlegen sollen, wie wir behandelt werden wollen, wenn wir in der Situation des anderen wären - um daraufhin so an dem anderen zu handeln" (304) - med et samstemmende citat fra Løgstups Norm og spontanitet. ${ }^{6}$

5. Jeg bruger denne betegnelse, til trods for dens fortrinsvist katolsk anvendelse, og følger i stedet brugen analytisk etik, hvor det behandlede diskuteres under denne overskrift. cf. U. Wessels, Die gute Samariterin. Zur Struktur der Supererogation, Ideen \& Argumente (Berlin - New York: de Gruyter 2002).

6. K.E. Løgstrup, Norm og spontanitet (København: Gyldendal 1972), 19. 
Denne fantasi eller forestillingsevne henter ganske vist sin næring fra den stadige "kommunikation" og tradition, der udgår fra Gudsrigets eskatologiske symbolik, næstekærlighed og efterfølgelse. Den har brug for den genuine kommunikation i politia Christi og for kirken som Kristi åndelige regimentes socialform. Her bliver - for at nævne et par eksempler - stedfortrædelse og forbøn formidlet videre. Her bliver syndsforladelse forstået som fornyelsen af friheden hinsides strafferettens muligheder formidlet videre. Her kunne man i dag også formidle en kulturel gæstfrihed videre i de kristne menigheder og kirker, som ikke umiddelbart kan indhentes i menneskerettighederne eller i flygtninge- og asylretten.

I centrum for Andersens lutherske reception af den politiske liberalisme står rekonstruktionen af den gyldne regel som indbegrebet af en naturlig-lovmæssig fornuft og dens reciprocitet. Sammenfattende:

ergibt sich das Bild eines lutherischen Christen, der sich als Bürger einem überlappenden Konsens über die beiden Prinzipien der Gerechtigkeit anschließen kann, und zwar 'aus den rechten Gründen'. Ein lutherischer Christ kann zum einen die Gerechtigkeitsprinzipien als gegenwärtigen Ausdruck der Nächstenliebe als Wohltun verstehen, und zum anderen die Konsensfähigkeit des Kerngedankens der Reziprozität in der Allgemeinheit der Goldenen Regel begründet sehen. Die entscheidende Voraussetzung dafür ... ist seine Fähigkeit, das Politische als selbständigen Bereich von dem eigentlichen religiösen Inhalt seiner Überzeugung zu trennen. Genau diese Trennlinie ist aber in der lutherischen Unterscheidung zwischen Geistlichem und Weltlichem impliziert ...” (305).

Det politiske subjekt i Andersens politiske etik er lutherske kristne forstået som samfundsborgere og ikke som kirkemedlemmer. Ud fra et tysk perspektiv kan man sammenfattende spørge: Er det politiske område kun en del af lutherske borgeres religiøse overbevisning, der hører hjemme i baggrundskulturen? Er det ikke snarere sådan, at kirken er den specifikt offentlige virkeliggørelse af en "post-politisk kommunikation" i det åndelige regimente (O. O’Donovan), 7 der adskiller sig fra den politiske dømmekraft i det verdslige regimente? Er det ikke muligt at rekonstruere den politiske fornuft selv og medmenneskelighedens sprog som "imaginære politiske institutioner" (C. Castoriadis)?

Oversat af Bo Kristian Holm

7. Oliver O'Donovan, The Ways of Judgment. The Bamption Lectures 2003 (Grand Rapids/Cambridge: Wm. B. Eerdsmann 2005), især del III. Life beyond Judment: Communication, 231-241.

8. Cornelius Castoriadis, Gesellschaft als imaginäre Institution. Entwurf einer politischen Philosophie (Frankfurt a/M: Suhrkamp 1990). 